\section{Hawk Migration}

TOM BEVERIDGE, Pathlow, Sask.

On April 12 it was my privilege to see a remarkable migratory movement of hawks, far surpassing any such movement I have ever seen. Pathlow, where we live, is ten miles

be commercialized. Fishermen are endlessly plied with boats and gear and tackle and togs, but all a berrypicker needs is a tin pail and his oldest duds. No wonder we rate nothing more than a lifted eyebrow.

All of which goes to prove that berry picking is one of the primal joys of life. Long before ever there were farmers or herdsmen or even hunters, people picked berries, and primitive simplicity still invests the act. No one ever got a stomach ulcer picking berries. All the complex and baffling anxieties of ultra-civilized living drop into the limbo as we luxuriate in the feeling that as long as we stay in the berry patch we need contend with nothing more complex than ants in the pant legs or a thistle in the unwary posterior.

Here the struggle of man against nature reverts to the ancient benignity of Eden. This is as near as one can ever hope to come to getting something for nothing. In fact in the berry patch we have Eden and Utopia rolled into one, for here, surely, is production for use and not for profit, and never any embarrassing problem of surpluses either.

One is reminded of Micah's vision, "They shall sit every one under his vine and under his fig tree, and none shall make them afraid." And our littlest berry picker echoes the dream as she stands, tin cup in hand, and croons, "I've a nice little bush all my own, and it's right here!" south and eight miles north of Melfort, which in turn is situated on No. 6 Highway, about 180 miles north of Regina.

It was a mild day with a good thaw. During the forenoon the wind was southwesterly about 15 m.p.h., and the sky fairly bright but overcast with a film of light clouds, and looked good for hawks. It was Monday, the day of the week when I have best opportunity to relax, so I looked out frequently.

The first noticeable movement occurred about 9:30 a.m. During the next half hour about 25 hawks in flocks from 3 to 8 passed. Three Redtails flew straight overhead. About 10 o'clock larger flocks began to appear, 10 or 15 , some 25 or more in circling swarms, sometimes a second flock appearing before the first was well out of sight. Most of them flew by well to the southeast, but smaller flocks and stragglers occasionally came right over. Redtails were far in the majority of those identified, but quite a number of Rough-legs, a few Marsh Hawks, some falcons (mostly Sparrow Hawks and three Golden Eagles). In forty minutes I had counted and estimated about 400 . During the next 15 minutes there were two more flights, one of 50 and the other of 75. I did not notice any significant movement for the next half hour, but at 11:30 a fresh movement was evident — a flight totalling 75 in the next four minutes.

From 11:45 to 12:05 I counted and estimated 400. From 12:05 to 12:35 there were 325 more - a total of 1350 in approximately 3 hours.

When I came out after dinner about 1 p.m., the wind had shifted to the east and the migration grounded. Probably not a dozen more hawks were seen during the rest of the day. 